\title{
Reactivity of a Silsesquioxane Organofunctionalized with 4-Amino-5- Phenyl-4H-[1,2,4]-Triazole-3-thiol: Complementary Characterization and an Application to Chronoamperometric Detection of L-Dopamine
}

\author{
Daniela Silvestrini Fernandes ${ }^{1} \cdot$ Vitor Alexandre Maraldi $^{1} \cdot$ Newton Luiz Dias Filho $^{2}$ - Devaney R. do Carmo ${ }^{1}$
}

Received: 1 May 2017 / Accepted: 19 April 2018 / Published online: 14 June 2018

(C) Springer Science+Business Media B.V., part of Springer Nature 2018

\begin{abstract}
This work describes the organofunctionalization and a complementary characterization and application of an octakis(3-chloropropyl)octasilsesquioxane (1) with 4-Amino-5-Phenyl-4H-[1,2,4]-Triazole-3-Thiol (2). The functionalized silsesquioxane (3) was characterized by nuclear magnetic resonance, X-ray diffraction, transmission electron microscopy and thermogravimetric analysis. After functionalized, the silsesquioxane can interact with copper chloride and subsequently with potassium hexacyanoferrate (III) (4). The hybrid composite formed (4) was characterized by FT-IR and diffuse reflectance. The compound $\mathbf{4}$ included into a work graphite paste electrode $(20 \% \mathrm{w} / \mathrm{w})$ was examined for chronoamperometric determination of L-Dopamine. The modified graphite paste electrode with compound 4 showed a linear response from $2.5 \times 10^{-5}$ at $4.0 \times 10^{-4} \mathrm{~mol} \mathrm{~L}^{-1}$. The modified graphite paste electrode with 4 showed a detection limit of $2.08 \times 10^{-4} \mathrm{~mol} \mathrm{~L}^{-1}$ with a relative standard deviation of $\pm 2 \%(n=3)$ and amperometric sensitivity of $0.136 \mathrm{~A} \mathrm{~mol} \mathrm{~L}^{-1}$.
\end{abstract}

Keywords Silsesquioxanes $\cdot$ Synthesis $\cdot$ Triazole $\cdot$ Characterization $\cdot$ Chronoamperometry $\cdot$ L-Dopamine

\section{Introduction}

Octakis(3-chloropropyl)octasilsesquioxanes are a family of compounds with general formula $\left(\mathrm{RSiO}_{1.5}\right)_{n}$. The cage compounds $\left(\mathrm{RSiO}_{1.5}\right)_{n}$, where $\mathrm{R}$ is an organic or inorganic group with $n=6,8,10$ or 12 , are a versatile class of building blocks units for the synthesis of new materials. In particular, much interest has been paid to cubic $\mathrm{T}_{8}$ octakis(3-chloropropyl)octasilsesquioxane $\left(\mathrm{R}-\mathrm{SiO}_{1.5}\right)_{8}$, consisting of a rigid, crystalline silica-like core that is perfectly defined spatially $(0.5-0.7 \mathrm{~nm})$ and that can be linked covalently to eight $\mathrm{R}$ groups [1-3]. These nano-building blocks can be functionalized with a variety of organic compounds [4-6].

Devaney R. do Carmo

docarmo@dfq.feis.unesp.br

1 Departamento de Física e Química, Universidade Estadual Paulista "Júlio de Mesquita Filho" - UNESP, Avenida Brasil, 56, CEP 15.385-000, Ilha Solteira, SP, Brazil

2 Departamento de Engenharia Mecânica, Universidade Estadual Paulista "Júlio de Mesquita Filho" - UNESP, Avenida Brasil, 56, CEP 15.385-000, Ilha Solteira, SP, Brazil
Due to the highly symmetrical three-dimensional nature of their nucleus, chloropropyl-T8 are good precursors for the production of hybrid organic-inorganic materials [7-12]. Hybrid organic-inorganic molecules like polyhedral oligomeric octakis(3-chloropropyl) octasilsesquioxane (chloropropyl-T8) can serve as precursors of several materials for distinct applications, such as optics, electronics, engineering and biosciences.

There are various companies and universities currently researching new materials using octakis(3-chloropropyl)octasilsesquioxanes (chloropropyl-T8) owing to its diverse properties, and which has contributed to a substantial increase in the number of patents and publications related to these materials. Such exponential increase in the number of researchers, publications, government incentive programs and industrial efforts conducting research on chloropropyl-T8 has resulted in these nanomaterials representing great potential in the field of nanoscience and nanotechnology [13].

Chloropropyl-T8 can be synthesized in several ways, depending on the nature of their precursor reagents, and the main reactions can be divided into two groups.

The first group includes the reactions that give rise to new $\mathrm{Si}-\mathrm{O}-\mathrm{Si}$ bonds with subsequent formation of 
other polyhedral. The second group of reactions includes processes that only involve variations in the structure and composition of substituent groups at the silicon atom, without affecting the silicon-oxygen skeleton of the molecule [14].

The most commonly used synthesis method is the hydrolytic condensation of its precursor monomer $\mathrm{RSiX}_{3}$, as described in Eq. 1:

$\mathrm{n} \mathrm{RSiX}_{3}+1.5 \mathrm{nH}_{2} \mathrm{O} \rightarrow\left(\mathrm{RSiO}_{1.5}\right) \mathrm{n}+3 \mathrm{nHX}$

Where $\mathrm{R}$ is a chemically stable substituent group such as methyl, phenyl or vinyl and $\mathrm{X}$ is a highly reactive substituent group, such as $\mathrm{Cl}$, OH or OR [14-19]. The hydrolytic condensation consists of two steps, in which the first is the hydrolysis of monosilane to give the corresponding trisilanol. This reaction is generally fast. The second step is the condensation of the trisilanol formed, this process has several steps involving the formation of various intermediate structures to ultimately produce different species and structures of octakis(3-chloropropyl)octasilsesquioxane [19].

As in the structure of the octakis(3-chloropropyl) octasilsesquioxanes there are highly reactive groups (1) such as $\mathrm{Cl}, \mathrm{OH}$ or $\mathrm{OR}$, they can be modified by a nucleophilic substitution process by inserting any organic/inorganic group of interest $[7,15]$. The reactivity of the $X$ groups (1) decreases in the following order: $\mathrm{Cl}>\mathrm{OH}>$ OCOR $>$ OR [16].

Thus, the octakis(3-chloropropyl)octasilsesquioxane containing the chlorine element at their ends, can be easily modified by this process known as functionalized organic/inorganic process, which is formed depending on new materials with different properties and applications [7].

Through this process the functionalized octakis(3chloropropyl)octasilsesquioxane have some properties enhanced, such as improved thermal and mechanical resistance, without affecting its characteristics [8, 20-22], and also increased adsorption capacity of metal ions in solution [23-29], thus the use of this procedure can generate types of octakis(3-chloropropyl)octasilsesquioxanes (chloropropylT8) with different properties and applications. They are also used as catalysts [7, 28], dendritic precursors [7, 29], polymer precursors [30], biocompatible materials, and as precursors for developing liquid crystals [31], homogeneous and heterogeneous catalysis [28, 32], electroactive films [33], additives [34, 35], antibacterials and biocides [36], and are also used in thin films and coatings for various applications, including nanocomposites [37-40].

However Electroanalytical field has few studies on modified octakis(3-chloropropyl)octasilsesquioxanes as substrates, acting as electron mediators or electrochemical sensors.

We present a characterization and thermal behavior of 2. A preliminary characterization (FT-IR) and a rigorous electrochemical study have been performed and published recently [41]. The compound $\mathbf{2}$ possesses $\mathrm{S}-\mathrm{C}-\mathrm{N}$ linkages and exhibits potential active sites for metal ions that may also be biologically active just like some other amineand thione-substituted trizoles [42]. Thus the compound 3 will behavior as a chelanting agent of $\mathrm{Cu}^{2+}$ ions and compound $\mathbf{4}$ can provide a good electron shuttle between the substrate (i.e. enzyme) and the electrode [41]. In addition, the presence of octakis(3-chloropropyl)octasilsesquioxane, which is an electron acceptor [33, 41] can provide a synergistic effect stabilizing microenvironment around the substrate. After rigorous characterization by voltammetry [41], the composite was tested in the chronoamperometric determination of L-Dopamine.

\section{Experimental}

\subsection{Reagents and Solutions}

Chemical reagents such as 3-chloropropyliltriethoxysilane, hydrochloric acid, 4-Amino-5-Phenyl-4H-[1,2,4]-Triazole3-Thiol (99\%) (2), potassium Hexacyanoferrate (III), LDopamine, potassium chloride, sodium hydroxide and all solvents were purchased commercially and all were of analytical grade (Sigma-Aldrich, Merck, Vetec) and were used as obtained. Supporting electrolytes solutions were prepared using Milli-Q water. The $0.1 \mathrm{~mol} \mathrm{~L}^{-1}$ of $\mathrm{NaOH}$ and $\mathrm{HCl}$ solutions were used to adjust the hidrogenionic concentrations.

\subsection{Synthesis of octakis(3-chloropropyl)octasilsesquioxane (1)}

The synthesis of octakis(3-chloropropyl)octasilsesquioxane (1) was followed according to the literature [36, 41].

Into round bottom flask, $800 \mathrm{~mL}$ of methanol, 27 $\mathrm{mL}$ of hydrochloric acid $(\mathrm{HCl})$ and $43 \mathrm{~mL}$ of 3chloropropyliltriethoxysilane were added and the system was kept under constant stirring at room temperature for 6 weeks. The, octakis(3-chloropropyl)octasilsesquioxane (1) was separated by filtration in a sintered plate funnel, yielding a white solid, which was then oven dried at $120{ }^{\circ} \mathrm{C}$ for 4 hours (yield of $35 \%$ ). Figure 1 illustrates a representative scheme of this synthesis.

\subsection{Preparation of octakis(3-} chloropropyl)octasilsesquioxane with 4-Amino-5-Phenyl-4H-[1,2,4]-Triazole-3-Thiol (3)

The organofunctionalization of octakis(3-chloropropyl)octasilsesquioxane (1) was performed in a 3-neck flask of 500 
Fig. 1 Preparation of octakis(3chloropropyl)octasilsesquioxane (1) and (b) organofunctionalization of octakis(3-

chloropropyl)octasilsesquioxane (1) with the modifying agent 4-Amino-5-Phenyl-4H-[1,2,4]-

Triazole-3-Thiol

(2)<smiles>ClCCC[Si]12O[Si]3(CCCCl)O[Si]4(CCCCl)O[Si](CCCCl)(O1)O[Si]1(CCCCl)O[Si](CCCCl)(O2)O[Si](CCCCl)(O3)O[Si](CCCCl)(O4)O1</smiles><smiles>Nn1c(S)nnc1-c1ccccc1</smiles>

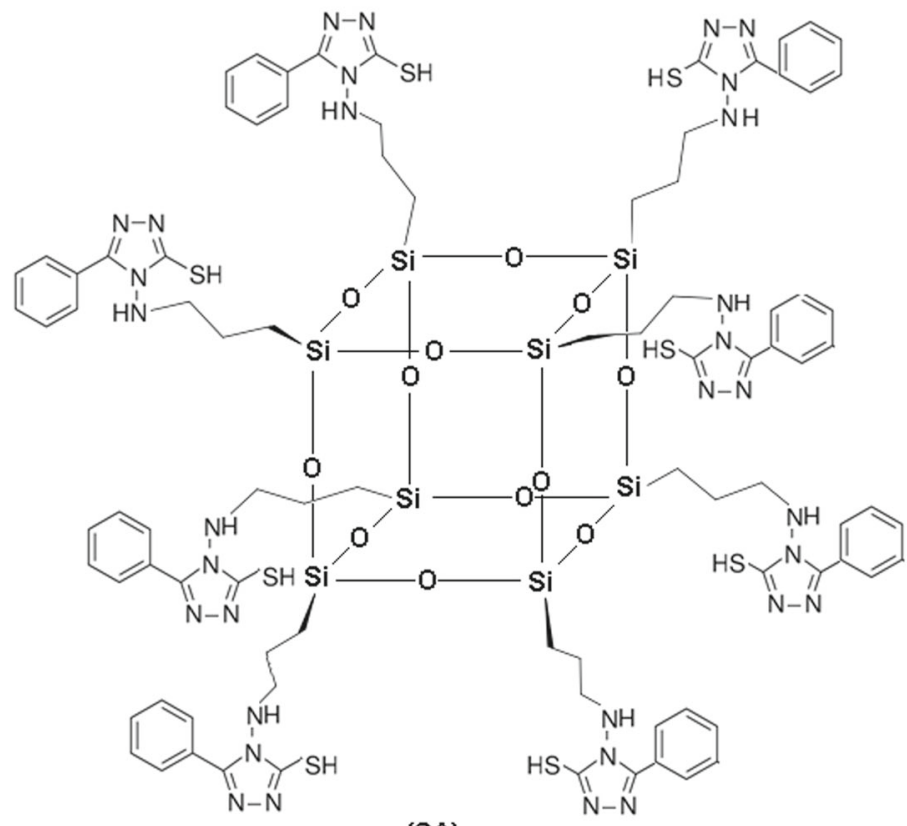

(SA)

\subsection{Reaction of Copper (II) and Hexacyanoferrate with Compound 3 - (4)}

The composite was prepared as described in literature [41]: $1.0 \mathrm{~g}$ of 3 was added in $25 \mathrm{~mL}$ of a $1.0 \mathrm{mmol} \mathrm{L}{ }^{-1}$ solution of copper chloride. After the mixture stirred for 60 minutes at room temperature, the solid was then filtered and washed with deionized water. The material resulting from this first the scheme of organofunctionalization process of $\mathbf{1}$ with 2 . 
step was oven dried at $70{ }^{\circ} \mathrm{C}$. In the second step, the material resulting in first step, was added in $25 \mathrm{~mL}$ of a $1.0 \mathrm{mmol}$ $\mathrm{L}^{-1}$ solution of potassium hexacyanoferrate (III), and the mixture was stirred for 60 minutes at room temperature and then the solid was thoroughly filtered, washed with deionized water and dried at $70{ }^{\circ} \mathrm{C}$. The materials resulting from this step were described by 4 .

\subsection{Characterization Measurements}

The electronic spectra (UV-Vis) were obtained with Guided wave model 260 spectrophotometer. All solid-state analyses of ${ }^{29} \mathrm{Si}(59.5 \mathrm{MHz})$ and ${ }^{13} \mathrm{C}-\mathrm{NMR}(75.4 \mathrm{MHz})$ were recorded on a Varian INOVA 300 spectrometer. The characterization by X-Ray diffraction was done using a Siemens D 5000 diffractometer with $\mathrm{CuK} \alpha(\lambda 1.5406 \AA$ radiation). The microstructure (TEM) was observed by microscope Philips brand - CM200. The thermal analysis was carried out using SDT 2960 and SDT Q600 from TA Instruments.

\subsection{Confection of Modified Graphite Paste Electrode}

The modified graphite paste electrodes were prepared by mixing the modified octakis(3-chloropropyl)octasilsesquioxane with graphite powder (20\% w/w) and nujol oil [42]. The MGPE was packed into an electrode body, consisting of a glass tube of i.d. $4 \mathrm{~mm}$ and height of $14 \mathrm{~cm}$, containing graphite paste equipped with a copper wire serving as an external electrical contact. The external surface of the electrode was smoothed on soft paper to produce a new surface.

\section{Techniques}

\subsection{Diffuse Reflectance (UV-Vis)}

The diffuse reflectance spectra of the bulk solid binuclear complex were recorded between 350 and $800 \mathrm{~nm}$ on a Guided Wave model 260 spectrophotometer, using a tungsten-halogen lamp as the radiation source, and detectors of Si and Ge.

\subsection{Nuclear Magnetic Resonance Analyses (NMR)}

All solid-state analyses of ${ }^{29} \mathrm{Si}(59.5 \mathrm{MHz})$ and ${ }^{13} \mathrm{C}$ NMR $(75.4 \mathrm{MHz})$ were recorded on a Varian INOVA 300 spectrometer. The samples were packed in zirconia rotors and spun at the magic angle at $4500 \mathrm{~Hz}$, a relaxation delay of 10.0 and $6.0 \mathrm{~s}$ for ${ }^{29} \mathrm{Si}$ and ${ }^{13} \mathrm{C}$ respectively. All chemical shifts are reported in parts per million ppm $(\delta)$ with reference to external tetramethylsilane (TMS).

\subsection{X-ray Diffraction (XRD)}

The $\mathrm{X}$ ray diffraction patterns (XRD) were obtained using a Siemens D 5000 diffractometer with $\mathrm{CuK} \alpha(\lambda 1.5406$ $\AA$ radiation), submitted to $40 \mathrm{kV}, 30 \mathrm{~mA}, 0.05^{\circ} \mathrm{s}^{-1}$ and exposed to radiation from 5 up to $80^{\circ}(2 \theta)$.

\subsection{Transmission Electron Microscopy (TEM)}

The transmission electron microscopy was performed using the microscope Philips brand - CM200, equipped with pole piece that allows to obtain high resolution images. It is operated at an accelerating voltage of $200 \mathrm{kV}$.

\subsection{Thermogravimetric Analysis (TG-DTA)}

The thermal analysis of the samples was carried out using two equipments - SDT 2960 from TA Instruments and SDT Q600 from TA Instruments. The thermogravimetric curves were obtained using approximately $6 \mathrm{mg}$ samples placed in alumina crucibles and subjected to a controlled air temperature program and nitrogen flow of $100 \mathrm{~mL}$ $\min ^{-1}$, with a heating rate of $10{ }^{\circ} \mathrm{C} \mathrm{min}^{-1}$. The sample analysis was performed at the temperature interval $25^{\circ} \mathrm{C}$ to $1200{ }^{\circ} \mathrm{C}$. As $\mathbf{1}$ contains chlorine in its composition, it releases chlorine gas when heated, which reacts with the crucible; therefore, it was subjected to heating at $700{ }^{\circ} \mathrm{C}$.

\subsection{Electrochemical Measurements}

For the amperometric determination of L-Dopamine was employed a AUTOLAB PGSTAT potentiostat with a platinum wire as the auxiliary electrode, $\mathrm{Ag} / \mathrm{AgCl}_{\text {(sat.) }}$ as reference electrode and graphite paste electrode as work electrode. The measurements were carried out at $25^{\circ} \mathrm{C}$. In tests using chronoamperometry method, and after testing different potential to define the constant potential to be applied in these studies $(0.71 \mathrm{~V}), 6$ aliquots $(30 \mu \mathrm{L}) \mathrm{L}$ Dopamine $\left(0.1 \mathrm{~mol} \mathrm{~L}^{-1}\right)$ were added to the electrochemical cell under strong stirring.

\section{Results and Discussion}

\subsection{Nuclear Magnetic Resonance of ${ }^{13} \mathrm{C}$ and ${ }^{29} \mathrm{Si}$ (NMR)}

The spectra of ${ }^{29} \mathrm{Si}$ and ${ }^{13} \mathrm{C}$ NMR of octakis(3chloropropyl)octasilsesquioxane (1) are represented by Fig. 2a and b, respectively. The spectrum of ${ }^{29} \mathrm{Si}$ NMR (Fig. 2a) of $\left[\mathrm{Cl}\left(\mathrm{CH}_{2}\right)_{3}\right]_{8} \mathrm{Si}_{8} \mathrm{O}_{12}$ (1) showed a resonance at $-67.38 \mathrm{ppm}$. This evidences the formation of the cubic 
Fig. 2 NMR spectrum in the solid state of the compound 1: a ${ }^{29} \mathrm{Si}$ and $\mathbf{b}{ }^{13} \mathrm{C}$

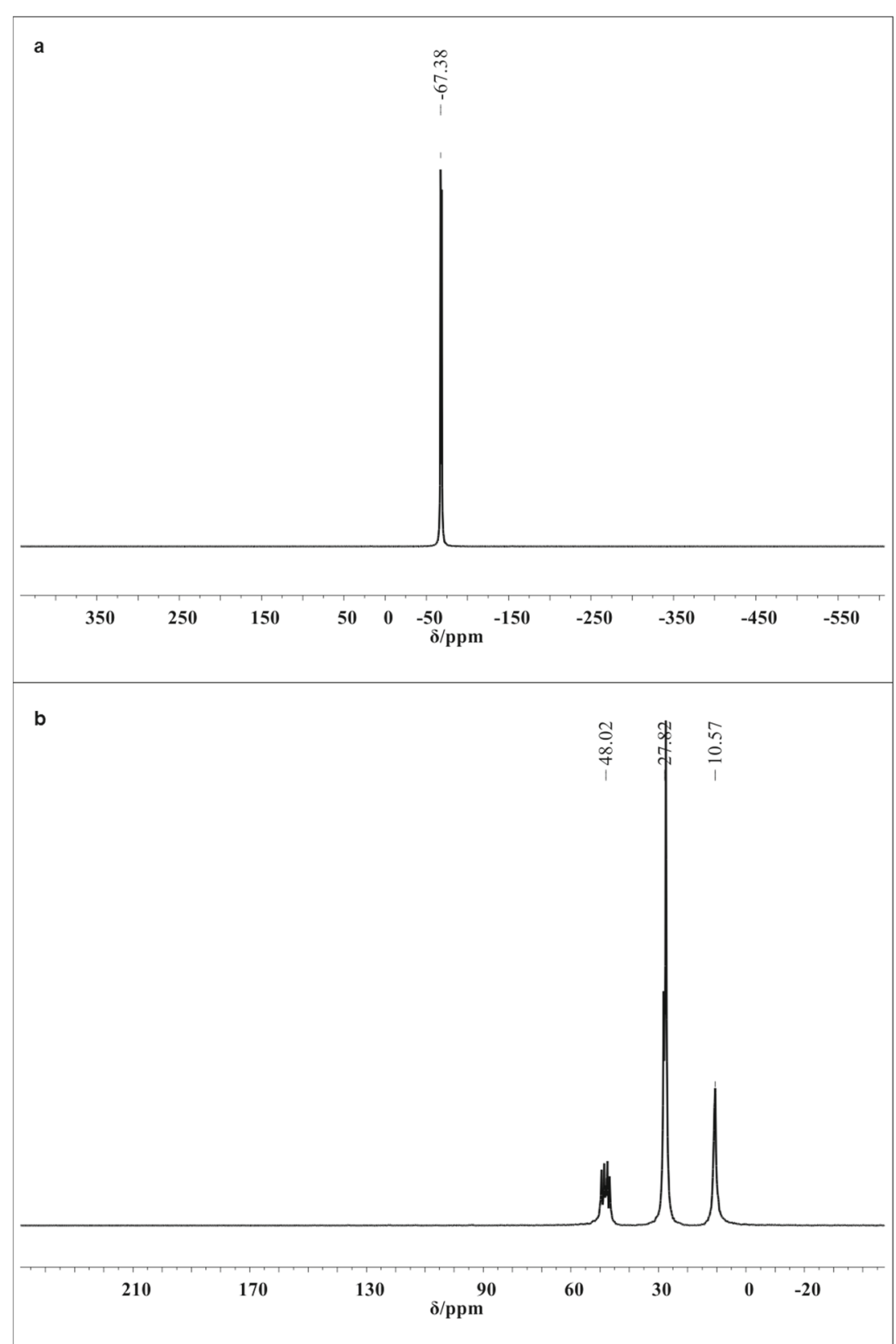

structure of silsesquioxane with symmetrical O-Si-O bonds, as described in the literature [7, 18, 43].

The spectrum NMR ${ }^{13} \mathrm{C}$ (Fig. 2b) shows three resonances attributed to three carbons of the propyl groups $(\alpha-$ 10.57, $\beta-23.82$ and $\gamma-48.02 \mathrm{ppm})$. These carbons are attributed as follows: $\alpha \mathrm{CH}_{2} \mathrm{CH}_{2} \mathrm{Si}, \beta \mathrm{CH}_{2} \mathrm{CH}_{2} \mathrm{CH}_{2}$ and $\gamma \mathrm{ClCH}_{2} \mathrm{CH}_{2}$ of the propyl group. These results clearly indicate the successful synthesis of octakis(3-chloropropyl) octasilsesquioxane [7, 18, 43].

Figure 3 illustrates the NMR ${ }^{29} \mathrm{Si}$ spectra in the solid state of compound $\mathbf{3}$. The spectrum shows, as expected, only one resonance at $-68,13 \mathrm{ppm}$ corresponding to silicon ( $\mathrm{Si}-\mathrm{O}-\mathrm{Si}$ ) $[7,18]$. The peak at $68.93 \mathrm{ppm}$ is assigned to $\mathrm{RSi}(\mathrm{OSi})_{3}$,
T4 signal. This result can affirm that the cubic structure of silsesquioxane (1) was kept after organofunctionalization.

Figure 4 shows the ${ }^{13} \mathrm{C}$ NMR spectrum of the solid to 3. It was observed eight resonance peaks, which are discriminated in the structure of the ligand molecule, inserted in Fig. 4. The chemical shifts observed at 9.98; 23.49 and $34.62 \mathrm{ppm}$ were assigned to the $\alpha$ carbon $\left(\mathrm{CH}_{2}-\mathrm{CH}_{2}-\underline{C H}_{2}-\mathrm{Si}\right), \beta\left(\mathrm{CH}_{2}-\underline{C H}_{2}-\mathrm{CH}_{2}-\mathrm{Si}\right)$ and $\gamma\left(\mathrm{CH}_{2}-\right.$ $\mathrm{CH}_{2}-\mathrm{CH}_{2}-\mathrm{Si}$ ) of the propyl group of $\mathrm{S}$, respectively. The shift in ppm 51.11 ( $\kappa$ was assigned to carbon N-NH- ${ }_{-} H_{2}-$ binder.

The existence of the peak at $34.62 \mathrm{ppm}(\gamma)$ is a strong evidence that not all terminals of the peripheral carbons 
Fig. $3{ }^{29} \mathrm{Si}$ NMR spectrum in the solid state of the compound 2

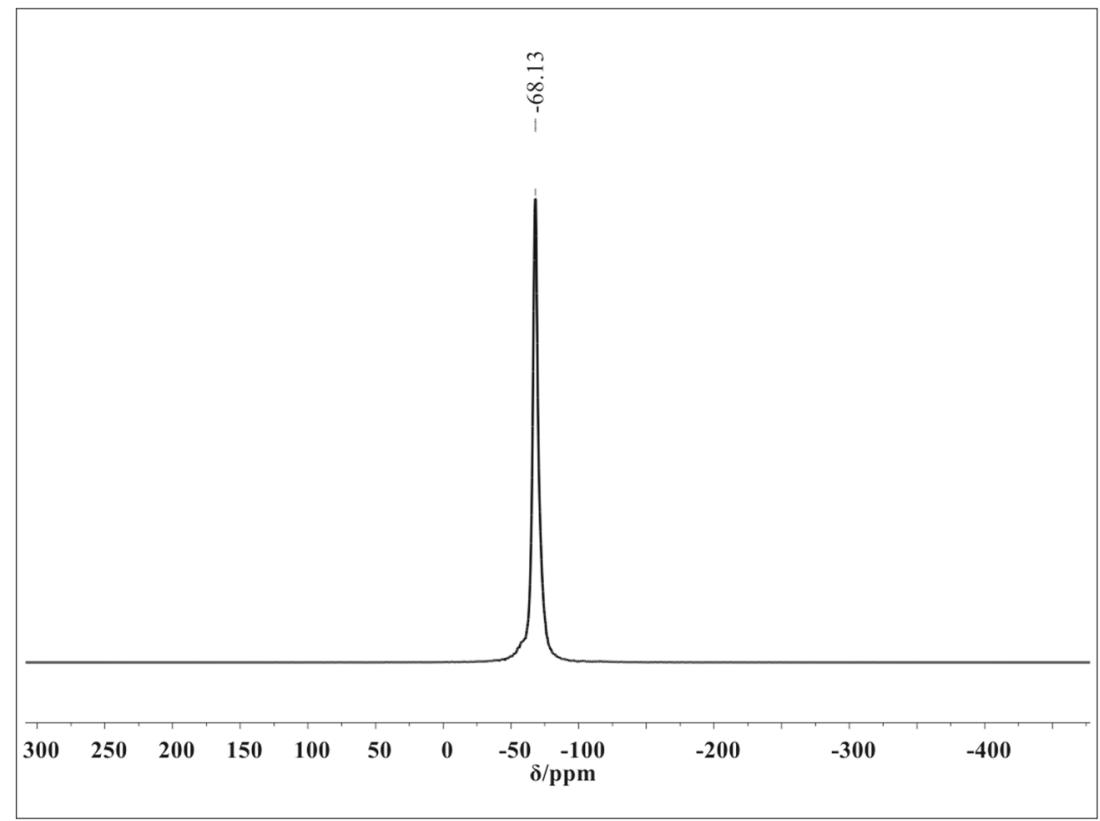

of $\mathbf{1}$ groups were actually functionalized. The chemical shifts observed at 128.96 and 151.94 ppm were assigned to the carbons of the phenyl group (a, b, c, d) and chemical shift at 156.52 and $162.58 \mathrm{ppm}$ were assigned to the carbons e and $\mathrm{f}$, respectively (see inserted structure in Fig. 4).

These assignments were established from ligand chemical shifts observed through solid state ${ }^{13} \mathrm{C}$ NMR as illustrated in Fig. 5.

Figure 5 illustrates the ligand solid state ${ }^{13} \mathrm{C}$ NMR solid, and the observed changes are strong evidence that functionalization has occurred through the triazole group
(N-NH- $\mathrm{CH}_{2}-$ ), because the chemical shift is profoundly dependent on its electronic environment [44-46].

\subsection{X-Ray diffraction (XRD)}

The X-Ray diffraction of $\mathbf{1}, \mathbf{2}$ and $\mathbf{3}$ are illustrated in Fig. 6. The $\mathbf{1}$ and $\mathbf{2}$ (Fig. 6a, b) were characterized by a large number of reflections, indicating that $\mathbf{1}$ and $\mathbf{2}$ exhibit a highly crystalline substance due to its regular structure. After the functionalization this crystallinity was low (Fig. 6c) and two broad peaks centered at $2 \theta=11.6^{\circ}$ and $20.7^{\circ}$ were observed, characteristic of the hybrid materials.
Fig. $4{ }^{13} \mathrm{C}$ NMR spectrum in the solid state of the compound 3

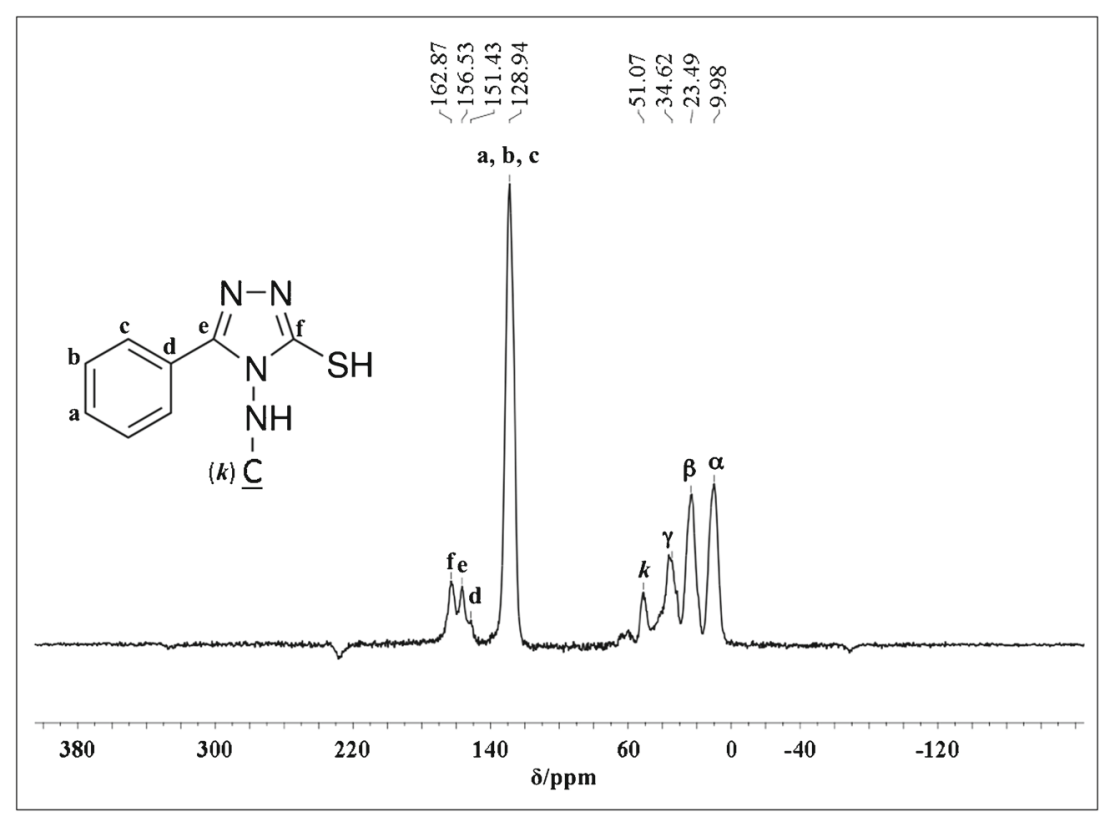


Fig. $5{ }^{13} \mathrm{C}$ NMR spectrum in the solid state of the compound 2

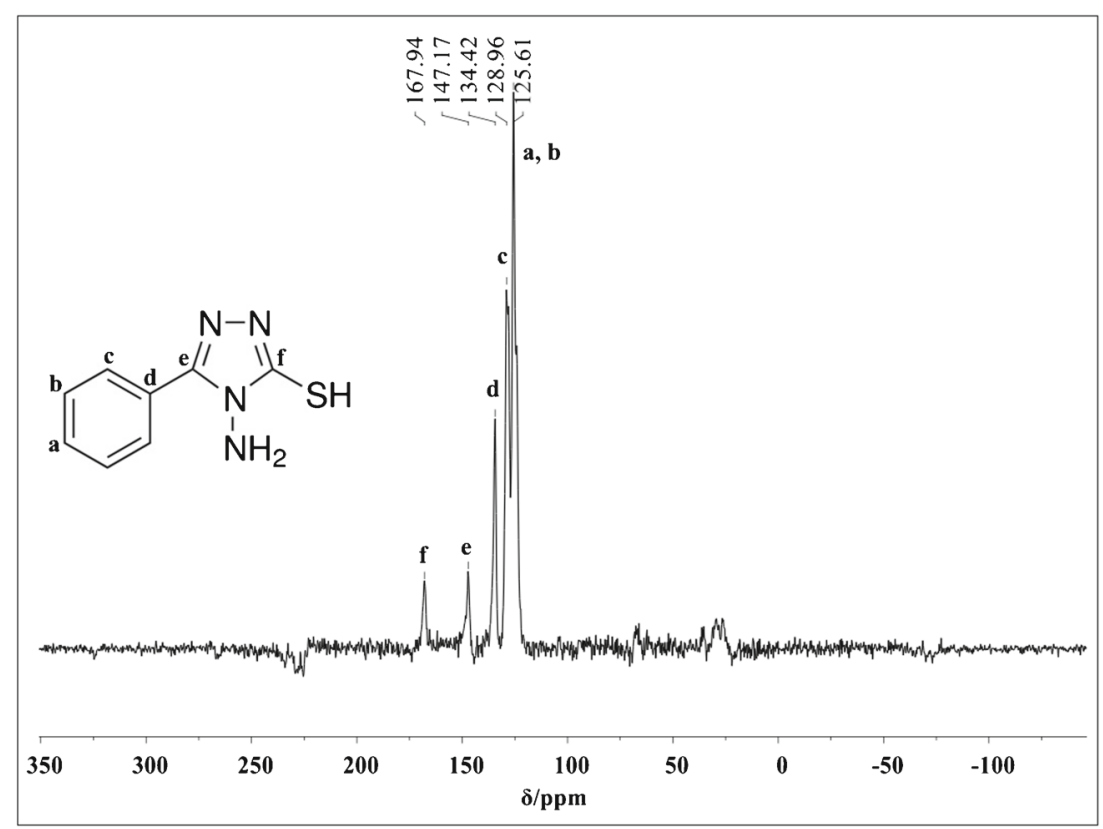

\subsection{Transmission Electron Microscopy (TEM)}

Figure 7 shows the transmission electron microscopic images of compounds 1 and $\mathbf{3}$ Fig. 7a and 7c, respectively. It was observed through TEM (in agreement with the SEM) cubic (Fig. 7a) and spherical (Fig. 7c) particles with nanometric dimensions were observed for $\mathbf{1}$ and $\mathbf{2}$, respectively. TEM revealed to $\mathbf{1}$ also a low crystallinity with standard X-ray diffraction with a very diffuse amorphous halo center, as shown in Fig. 7b. After functionalization, the topography has been drastically modified and central halo performed more amorphous (Fig. 7d). The final morphology is a dispersion of spherical chloropropyl-T8-rich domains produced by a typical nucleation-growth process [47]. This
Fig. 6 X-ray diffractograms of $\mathbf{a} \mathbf{1}, \mathbf{b} \mathbf{2}$ and $\mathbf{c} \mathbf{3}$
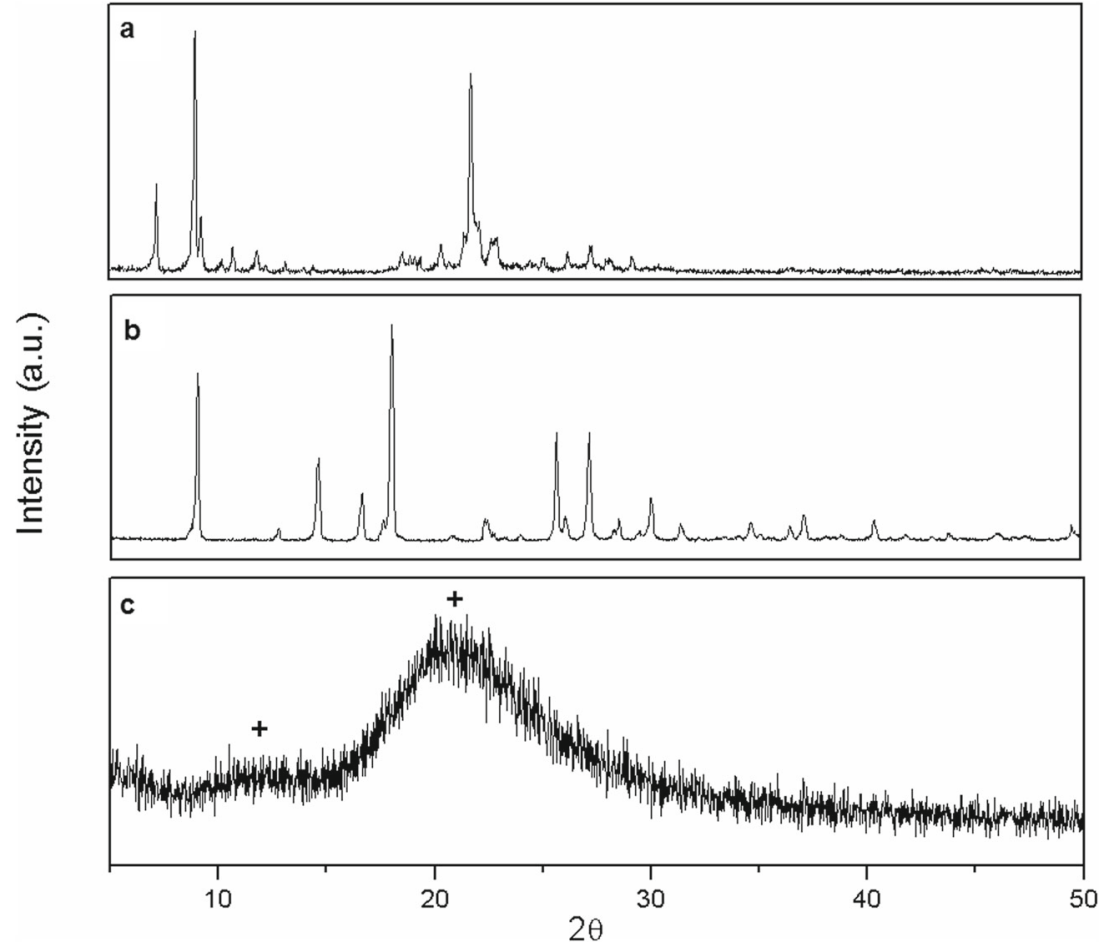
Fig. 7 Photomicrographs pattern X-ray: a, b 1 and $\mathbf{c}, \mathbf{d} \mathbf{3}$ (TEM) and its diffraction

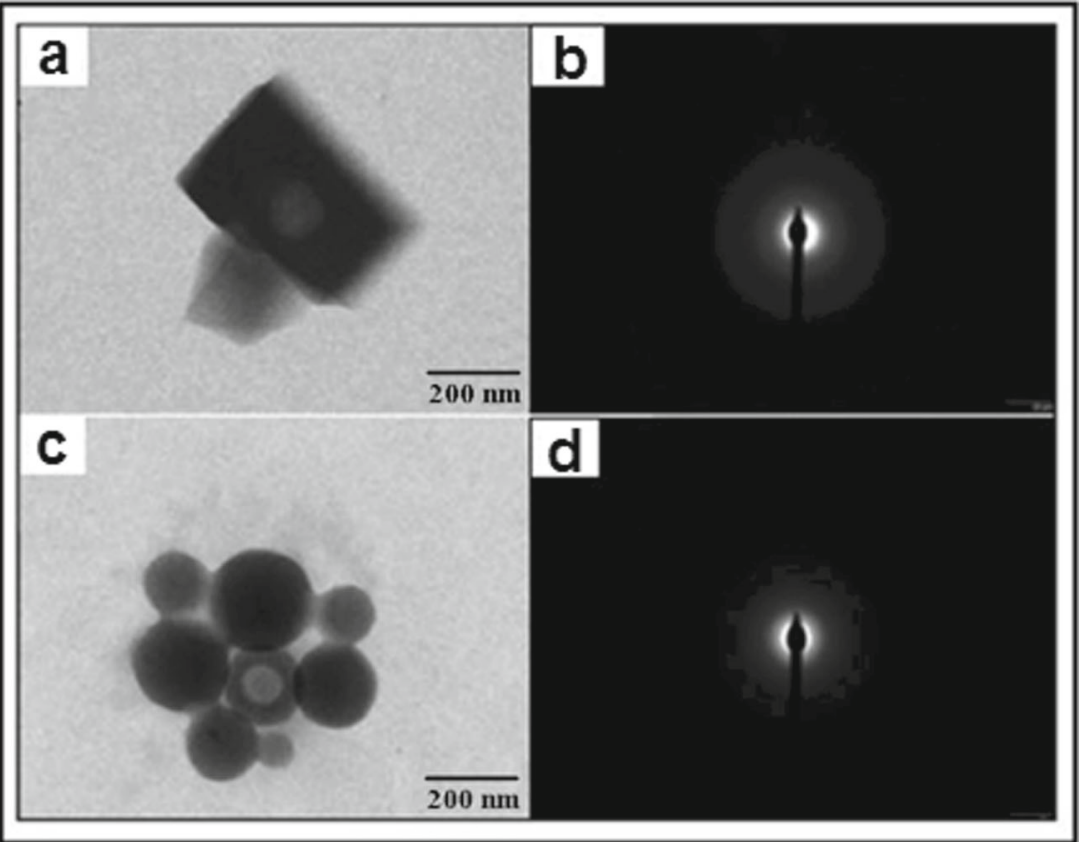

fact was in agreement with the XRD data shown for the $\mathbf{1}$ and 3.

\subsection{Thermogravimetric Analysis TG - DTA}

The thermogram of $\mathbf{1}$ in nitrogen atmosphere (Fig. 8a) showed two mass loss phases. The first stage was from 350 to $450{ }^{\circ} \mathrm{C}(68 \%)$ and the second was from 450 to $650{ }^{\circ} \mathrm{C}(7 \%)$ attributed to the oxidation of organic matter $[48,49]$ and the decomposition of residual groups $\mathrm{SiCH}_{2}$ [50-52] in the sample. The residue was $25 \%$ and based mainly on silica.

The thermogram of 2 (Fig. 8b) showed two mass loss stages, the first from 100 to $300{ }^{\circ} \mathrm{C}(47 \%)$ attributed to the release of physically adsorbed water $(5 \%)$ and loss of organic matter $(42 \%)$, resulting in its degradation. The second stage was from 300 to $700{ }^{\circ} \mathrm{C}(50 \%)$, which can also be attributed to oxidation of the organic matter (phenyl, triazole groups of compound 2) (Table 1).

Table 1 Thermogravimetric Analysis of SS, APhTT and SA

Materials Temperature $\left({ }^{\circ} \mathrm{C}\right)$ Weight Loss $(\%)$ Interpretation

\begin{tabular}{|c|c|c|c|}
\hline \multirow[t]{2}{*}{ SS } & $350-450$ & 68 & Organic matter \\
\hline & $450-650$ & 7 & Groups $\mathrm{SiCH}_{2}$ \\
\hline \multirow[t]{2}{*}{ APhTT } & $100-300$ & 47 & $\begin{array}{l}\text { Water and organic } \\
\text { matter }\end{array}$ \\
\hline & $300-700$ & 50 & $\begin{array}{l}\text { Phenyl and triazole } \\
\text { groups }\end{array}$ \\
\hline \multirow[t]{2}{*}{ SA } & $100-420$ & 36 & $\begin{array}{l}\text { Water and propyl, } \\
\text { phenyl and triazole } \\
\text { groups }\end{array}$ \\
\hline & $420-800$ & 25 & Groups $\mathrm{SiCH}_{2}$ \\
\hline
\end{tabular}

The thermogram of $\mathbf{3}$ (Fig. 8c) showed practically two mass loss stages the first at $100-420{ }^{\circ} \mathrm{C}(36 \%)$ where (3\%) attributed to physically adsorbed water loss of the

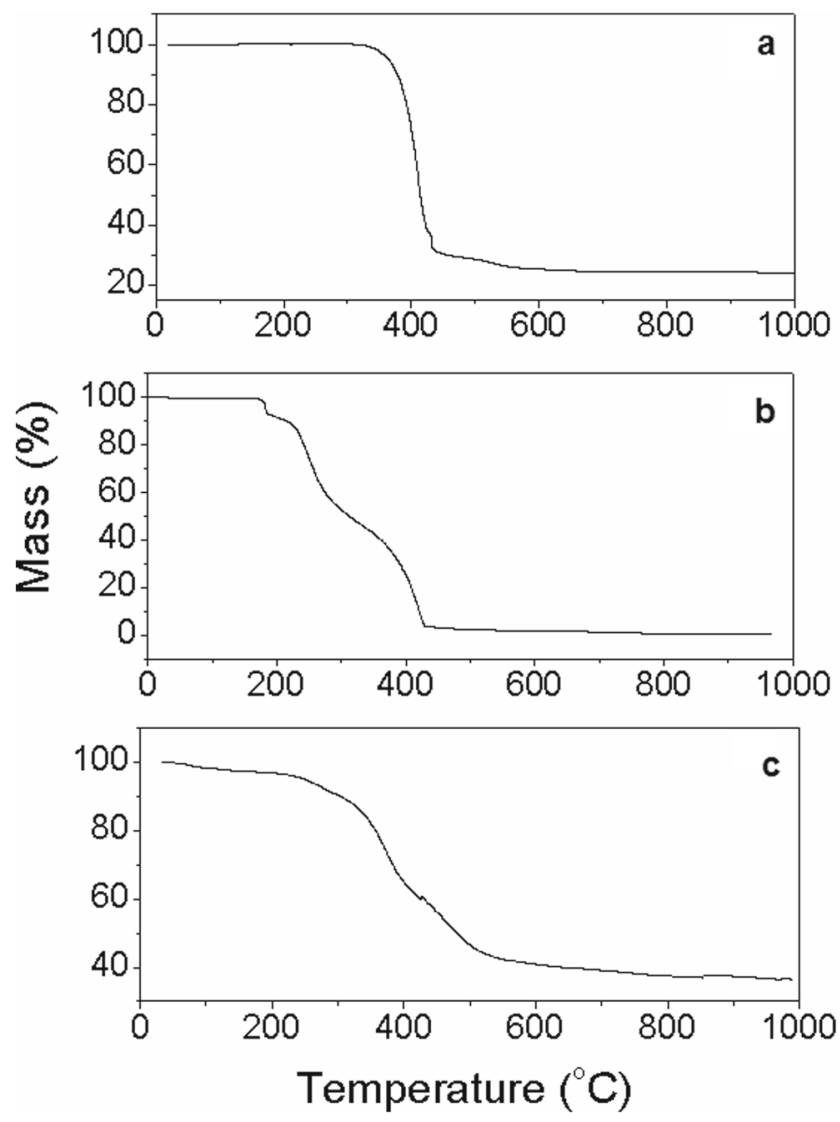

Fig. 8 Thermogram of compounds a 1 under a $\mathrm{N}_{2}$ atmosphere, b 2 under a $\mathrm{N}_{2}$ atmosphere and $\mathbf{c} \mathbf{3}$ under a $\mathrm{N}_{2}$ atmosphere 
Fig. 9 UV-Vis spectrum of: a 4 and $\mathbf{b} \mathbf{3}$

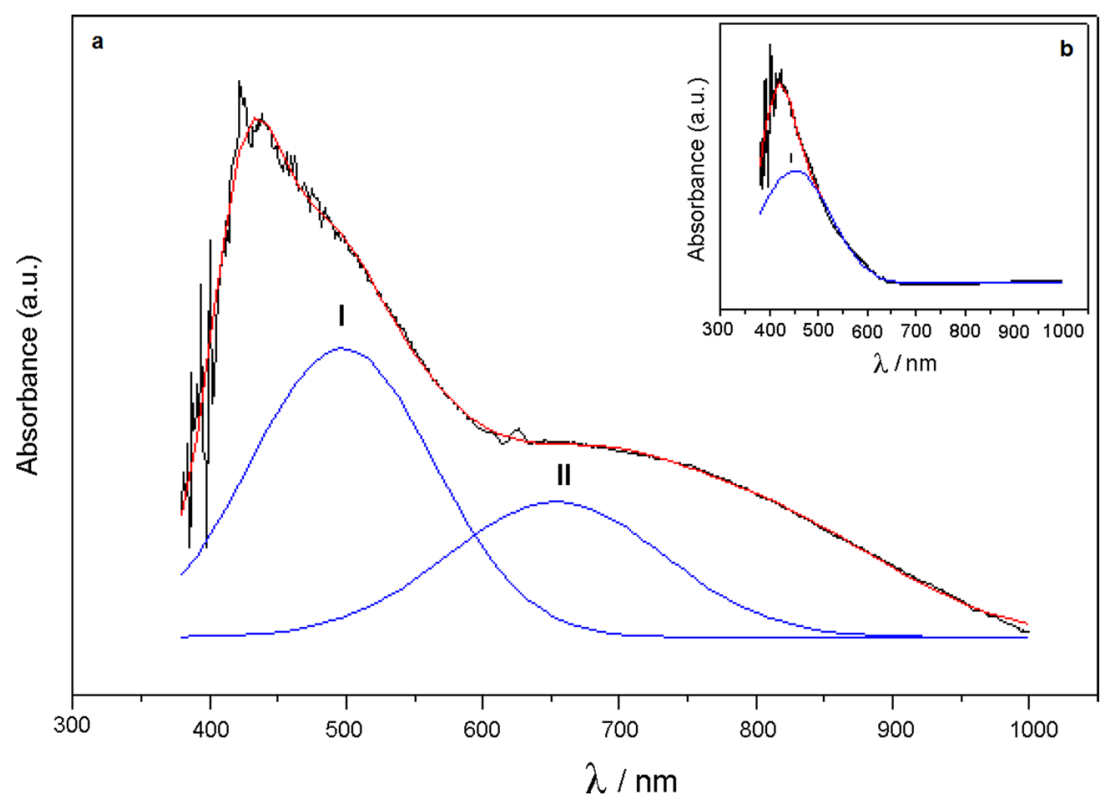

sample and $33 \%$ was attributed to the cleavage of C-C or $\mathrm{C}-\mathrm{Si}$ bonds. In the $420-800{ }^{\circ} \mathrm{C}$ temperature range the second mass loss stage $(25 \%)$ was observed, attributed to decomposition of residual groups $\mathrm{SiCH}_{2}$. In this case the residue of $39 \%$ and based mainly on silica. Additionally, it was observed that the materials $\mathbf{1}$ and $\mathbf{3}$ had some thermal stability up to temperatures of around $350{ }^{\circ} \mathrm{C}$.

The thermograms of the materials in air atmosphere (results not shown here) showed a similar behavior as those in nitrogen atmosphere, but this weight loss is attributed to the cleavage of C-C or C-Si bonds. Comparatively, within the experimental range, all the TGA curves of the materials in nitrogen atmosphere were more thermally stable than one in air atmosphere.

\subsection{Application of Compound 3}

As an example of the reactional versatility of the hybrid composite to form bimetallic complexes, 3 was firstly reacted with $\mathrm{Cu}^{2+}$, and then with potassium hexacyanoferrate (III) to form (4), however the compound 4 was obtained in two stages (item 2.4) [41]. The success
Fig. 10 Cyclic voltammograms of graphite paste modified with compound $4(\mathrm{KCl}, 20 \% \mathrm{w} / \mathrm{w}, \mathrm{v}$ $\left.=20 \mathrm{mV} \mathrm{s}^{-1}, 1.00 \mathrm{~mol} \mathrm{~L}^{-1}\right)$

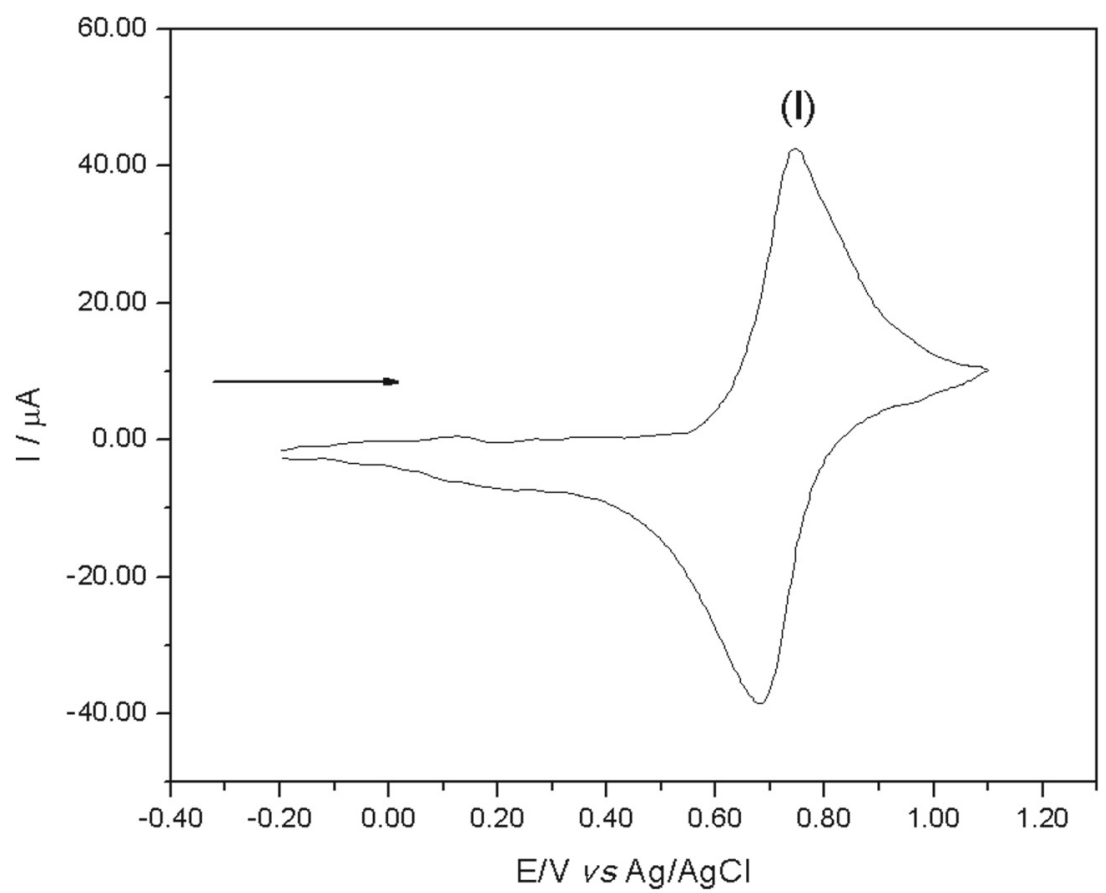


of this synthesis was previously verified by FT-IR [41] and then verified by diffuse reflectance. As illustrated by Fig. 9 , the composite 3 showed only one absorption at $450 \mathrm{~nm}$, attributed to the interactions of the d-d type, but for $\mathbf{4}$ was found a band of metal intervalence metal to metal charge transfer (MMCT) at $700 \mathrm{~nm}$ [53].

The compound $\mathbf{4}$ was characterized by cyclic voltammetry as shown in Fig. 10. With the voltammogram of $4(20 \% \mathrm{w} / \mathrm{w})$, a redox pair (peak I) was observed with a formal potential $E^{\theta^{\prime}}=0.71 \mathrm{~V}(v=20$ $\mathrm{mV} \mathrm{s}^{-1} ; \mathrm{KCl} 1.0 \mathrm{M}$ ), attributed to the redox process $\mathrm{Cu}^{\mathrm{II}} \mathrm{Fe}^{\mathrm{II}}(\mathrm{CN})_{6} / \mathrm{Cu}^{\mathrm{II}} \mathrm{Fe}^{\mathrm{III}}(\mathrm{CN})_{6}$ of the binuclear complex formed on the material surface (3).

A rapid and direct application of hybrid composite was tested in the chronoamperometric determination of L-Dopamine. Figure 11 illustrates a chronoamperogram obtained by adding of 6 aliquots $(30 \mathrm{uL})$ of L-Dopamine $(0.1 \mathrm{M})$ to the electrochemical cell under strong and constant stirring. This technique was chosen in order to evaluate the effect of diffusion of the drug to the surface of the electrode where the electrochemical reactions occur.

The inserted graphic in Fig. 11 illustrates the analytical curve used to determinate L- Dopamine using chronoamperometry.

The modified electrode showed a linear response from $2.5 \times 10^{-5}$ to $4.0 \times 10^{-4} \mathrm{~mol} \mathrm{~L}^{-1}$ with the corresponding equation $Y(\mathrm{~A})=6.18 \times 10^{-7}+0.136$ [L-Dopamine], and a correlation coefficient of $\mathrm{r}^{2}=0.997$. The method showed a detection limit of $1.30 \times 10^{-5} \mathrm{~mol} \mathrm{~L}{ }^{-1}$ with a relative standard deviation of $\pm 4 \%(n=3)$ and amperometric sensitivity of $0.136 \mathrm{~A} \mathrm{~mol} \mathrm{~L}^{-1}$.

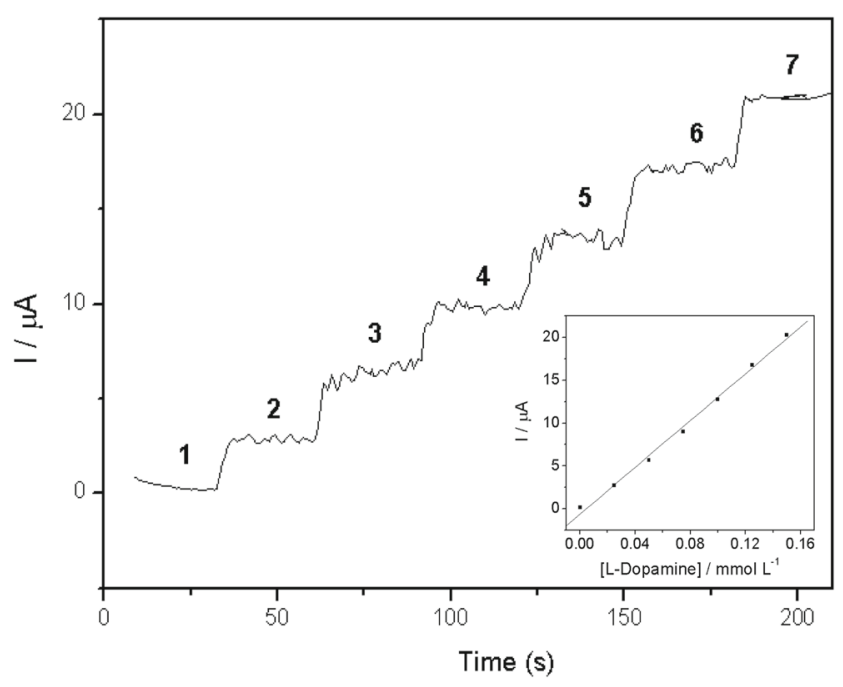

Fig. 11 Chronoamperogram obtained by adding a of 6 aliquots (30 $\mathrm{uL})$ of L-Dopamine $(0.1 \mathrm{M})$. Inserted Graphic: The analytical curve used to determinate L-Dopamine using chronoamperogram (constant potential of $0.71 \mathrm{~V}, 30 \mathrm{~s}$ time interval, $\mathrm{KCl}, 1.00 \mathrm{~mol} \mathrm{~L}^{-1}, \mathrm{pH} 7.00$ )

\section{Conclusion}

The complementary study of NMR and diffuse reflectance in the solid state together with XRD, SEM and TEM confirm that organofunctionalization of octakis(3-chloropropyl)octasilsesquioxane (1) with 4-Amino-5-Phenyl-4H[1,2,4]-Triazole-3-Thiol (2) was successfully carried out. It was observed that the materials $\mathbf{1}$ and $\mathbf{3}$ had some thermal stability up to temperatures of around $350{ }^{\circ} \mathrm{C}$. The novel material was tested with success in the determination of L-Dopamine using graphite paste electrode and chronoamperometric technique. The electrode is chemical and electrochemically stable, has low detection limit and is suitable for determination of L-Dopamine. These nanostructured materials could be employed as starting reagent for synthesis of hybrid compounds.

Acknowledgments The authors would like to express their gratitude for the financial support by the Fundação de Amparo à Pesquisa do Estado de São Paulo (FAPESP- Proc. 2012/05438-1 and 2012/113060) and Coordenação de Aperfeiçoamento de Pessoal de Nível Superior (CAPES).

Compliance with Ethical Standards This study was funded by Fundação de Amparo à Pesquisa do Estado de São Paulo. Grant number 2012/05438-1 and 2012/11306-0.

Conflict of interests The authors declare that they have no conflict of interest.

\section{References}

1. Provatas A, Matisons JG (1997) Silsesquioxanes: synthesis and applications. Trends Polym Sci 5(10):327-332

2. Zhang C, Laine RM (2000) Hydrosilylation of Allyl Alcohol with $\left[\mathrm{HSiMe}_{2} \mathrm{OSiO}_{1.5}\right]_{8}$ : Octa(3-hydroxypropyldimethylsiloxy) octasilsesquioxane and Its Octamethacrylate Derivative as Potential Precursors to Hybrid Nanocomposites. J Am Chem Soc 122 (29):6979-6988. https://doi.org/10.1021/ja000318r

3. Baney RH, Itoh M, Sakakibara A, Suzuki T (1995) Silsesquioxanes. Chem Rev 95(5):1409-1430

4. Blanco I, Abate L, Bottino FA (2014) Synthesis and thermal properties of new dumbbell-shaped isobutyl-substituted POSSs linked by aliphatic bridges. J Therm Anal Calorim 116(1):5-13. https://doi.org/10.1007/S10973-013-3487-3

5. Blanco I, Bottino FA, Abate L (2016) Influence of $n$-alkyl substituents on the thermal behavior of Polyhedral Oligomeric Silsesquioxanes (POSSs) with different cage's periphery. Thermochim Acta 623:50-57. https://doi.org/10.1016/j.tca.2015.11. 013

6. Zhao B, Cheng L, Bei Y, Wang S, Cui J, Zhu H, Li X, Zhu Q (2017) Grafted polybenzimidazole copolymers bearing polyhedral oligosilsesquioxane pendant moieties. Eur Polym J 94:99-110. https://doi.org/10.1016/j.eurpolymj.2017.05.024

7. Dutkiewicz M, Maciejewski H, Marcieniec B (2009) Functionalization of polyhedral oligomeric silsesquioxane (POSS) via nucleophilic substitution. Synthesis 1(12):2019-2024. https://doi.org/10.1055/s-0029-1216807 
8. Gnanasekaran D, Madhavan K, Reddy BSR (2009) Developments of Polyhedral Oligomeric Silsesquioxanes (POSS), POSS Nanocomposites and their Applications: a Review. J Sci Ind Res 68(6):437-464

9. Skaria S, Schricker SR (2010) Synthesis and characterization of Inorganic-Organic hybrid materials derived from polysilsesquioxanes (POSS). J Macromol Sci 47(5):381-391. https://doi.org/10.1080/10601321003659440

10. Yandek GR, Moore BM, Ramirez SM, Mabry JM (2012) Effects of peripheral architecture on the properties of aryl polyhedral oligomeric silsesquioxanes. J Phys Chem: C 116(31):1675516765. https://doi.org/10.1021/jp3039708

11. Blanco I, Bottino FA, Cicala G, Cozzo G, Latteri A, Recca A (2015) Synthesis and Thermal characterization of new dumbbell shaped POSS/PS nanocomposites: Influence of the symmetrical structure of the nanoparticles on the dispersion/aggregation in the polymer matrix. Polym Compos 36(8):1394-1400. https://doi.org/10.1002/pc.23045

12. Kowalewska A (2017) Self-Assembling Polyhedral silsesquioxanes structure and properties. Curr Org Chem 21(14):1243-1264. https://doi.org/10.2174/1385272821666170303103747

13. Phillips SH, Haddad TS, Tomczak SJ (2004) Developments in nanoscience: polyhedral oligomeric silsesquioxane (POSS)polymers. Curr Opin Solid State Mater Sci 8(1):21-29. https://doi.org/10.1016/j.cossms.2004.03.002

14. Lu TL, Liang GZ, Kou KG (2005) Synthesis and characterization of cage octa (cyclohexyl silsesquioxane). J Mater Sci 40(18):4721-4726. https://doi.org/10.1007/s10853-005-0839-9

15. Cordes DB, Lickiss PD, Rataboul F (2010) Recent developments in the chemistry of cubic polyhedral oligosilsesquioxanes. Chem Rev 110(4):2081-2173. https://doi.org/10.1021/cr900201r

16. Voronkov MG, Lavrent'yev VL (1982) Polyhedral Oligosilsesquioxanes and their homo Derivatives. Top Curr Chem 102:199-223. https://doi.org/10.1007/3-540-11345-212

17. Li G, Wang L, Ni H, Pittman Junior CU (2001) Polyhedral Oligomeric Silsesquioxane (POSS) Polymers and Copolymers: A Review. J Inorg Organomet Polymer 11(3):123-154. https://doi.org/10.1023/A:1015287910502

18. Marciniec B, Dutkiewicz M, Maciejewski H, Kubicki M (2008) New Effective Method of Synthesis and Structural Characterization of Octakis(3-chloropropyl)octasilsesquioxane. Organomet 27(4):793-794. https://doi.org/10.1021/om700962x

19. Pescarmona PP, Maschmeyer T (2001) Review: Oligomeric silsesquioxanes: synthesis, Characterization and Selected Applications. Aust J Chem 54(10):583-596. https://doi.org/10.1071/ $\mathrm{CH} 02003$

20. Su CH, Chiu YP, Teng CC, Chiang CL (2010) Preparation, characterization and thermal properties of organic-inorganic composites involving epoxy and polyhedral oligomeric silsesquioxane (POSS). J Polym Res 17(5):673-681. https://doi.org/10.1007/ s10965-009-9355-y

21. Takala M, Karttunen M, Pelto J, Salovaara P, Munter T, Honkanen M, Auletta T, Kannus K (2008) Thermal, mechanical and dielectric properties of nanostructured epoxy-polyhedral oligomeric silsesquioxane composites. Dielectr Electr Insul 15(5):1224-1235. https://doi.org/10.1109/TDEI.2008.4656229

22. Zhao Y, Schiraldi DA (2005) Thermal and mechanical properties of polyhedral oligomeric silsesquioxane (POSS)/polycarbonate composites. Polymer 46(25):11640-11647. https://doi.org/10. 1016/j.polymer.2005.09.070

23. Alfaya RVS, Fujiwara ST, Gushikem Y, Kholin YV (2004) Adsorption of metal halides from ethanol solutions by a 3-n-propylpyridiniumsilsesquioxane chloride-coated silica gel surface. J Colloid Interf Sci 269(1):32-36. https://doi.org/10.1016/ S0021-9797(03)00611-8
24. Soares LA, Da Silveira TFS, Silvestrini DR, Bicalho UO, Do Carmo DR (2013) Use of a silsesquioxane organically modified with 4-amino-5-(4-pyridyl)-4H-1,2,4-triazole-3thiol (APTT) for adsorption of metal ions. Int J Chem 5(1):39-48. https://doi.org/10.5539/ijc.v5n1p39

25. Dias Filho NL, Costa RM, Marangoni F (2008) Adsorption of transition-metal ions in ethanol solution by a nanomaterial based on modified silsesquioxane. Colloid Surf A 317(1-3):625-635. https://doi.org/10.1016/j.colsurfa.2007.11.050

26. Fujiwara ST, Gushikem Y, Alfaya RVS (2001) Adsorption of $\mathrm{FeCl}_{3}, \mathrm{CuCl}_{2}$ and $\mathrm{ZnCl}_{2}$ on silsesquioxane 3-npropylpyridiniumchloride polymer film adsorbed on $\mathrm{Al}_{2} \mathrm{O}_{3}$ coated silica gel. Colloid Surf A 178(1-3):135-141. https://doi.org/10. 1016/S0927-7757(00)00685-3

27. Vieira EG, Soares IV, Da Silva NC, Perujo SD, Do Carmo DR, Dias Filho NL (2013) Synthesis and characterization of 3-[(thiourea)-propyl]-functionalized silica gel and its application in adsorption and catalysis. J Chem 37(7):1933-1943. https://doi.org/10.1039/C3NJ00083D

28. Fina A, Tabuani D, Carniato F, Frache A, Boccaleri E, Camino G (2006) Polyhedral oligomeric silsesquioxanes (POSS) thermal degradation. Acta 440(1):36-42. https://doi.org/10.1016/j.tca. 2005.10.006

29. Ropartz L, Morris RE, Foster DF, Cole-Hamilton DJ (2002) Phosphine-containing carbosilane dendrimers based on polyhedral silsesquioxane cores as ligands for hydroformylation reaction of oct-1-ene. J Mol Catal Chem 182:99-105. https://doi.org/S13811169(01)00502-7

30. Pielichowski K, Njuguna J, Janowski B, Pielichowski J (2006) Polyhedral Oligomeric Silsesquioxanes (POSS)-containing Nanohybrid Polymers. Adv Polym Sci 201:225-296. https://doi. org/10.1007/12077

31. Lin TH, Chen WZ (2010) Photo-Alignment Effect in LiquidCrystal films containing nanoparticles and Azo-Dye. Key Eng Mat 428:276-279. https://doi.org/10.4028/www.scientific.net/KEM. 428-429.276

32. Abbenhuis HCL (2000) Advances in Homogeneous and Heterogeneous Catalysis with Metal-Containing Silsesquioxanes. Chem Eur J 6(1):25-32. https://doi.org/10.1002/(SICI)1521-3765 (20000103)6:1<25::AID-CHEM25>3.0.CO;2-Y

33. Morán M, Casado CM, Cuadrado I (1993) Ferrocenyl substituted octakis(dimethylsiloxy) octasilsesquioxanes: a new class of supramolecular organometallic compounds. synthesis, characterization, and electrochemistry. Organomet 12(11):43274333

34. Devaux E, Rochery M, Bourbigot S (2002) Polyurethane/clay and polyurethane/POSS nanocomposites as flame retarded coating for polyester and cotton fabrics. Fire Mater 26(4-5):149-154. https://doi.org/10.1002/fam.792

35. Wann DA, Less JR, Rataboul F, McCaffrey PD, Reilly AM, Robertson HE, Lickiss PD, Rankin DWH (2008) Accurate Gas-Phase Experimental Structures of Octasilsesquioxanes $\left(\mathrm{Si}_{8} \mathrm{O}_{12} \mathrm{X}_{8} ; \mathrm{X}=\mathrm{H}, \mathrm{Me}\right)$. Organomet 27(16):4183-4187. https://doi.org/10.1021/om800357t

36. Chojnowski J, Fortuniak W, Rościszewski P, Werel W, Łukasiak J, Kamysz W, Haasa A (2006) Polysilsesquioxanes and Oligosilsesquioxanes Substituted by Alkylammonium Salts as Antibacterial Biocides. J Inorg Organomet Polym Mater 16(3): 219-230. https://doi.org/10.1007/s10904-006-9048-5

37. Ro HW, Park ES, Soles CL, Yoon DY (2010) Structure-Property Relationships for methylsilsesquioxanes. Chem Mater 22(4): 1330-1339. https://doi.org/10.1021/cm901771y

38. Da Silveira TFS, Silvestrini DR, Bicalho UO, Do Carmo DR (2013) Voltammetric Study of a Cubic Silsesquioxane Organically Modified with Imidazole and their Subsequent Reaction with 
Cadmium and Hexacyanoferrate (III). Int J Electrochem Sci 8(1):872-886. https://doi.org/10.1155/2014/695954

39. Do Carmo DR, Silvestrini DR, Barud HS, Dias Filho NL, Bicalho UO, Soares LA (2014) A Silsesquioxane Organically Modified with 4-Amino-5-(4-pyridyl)-4H -1,2,4-triazole3-thiol: Thermal Behavior and Its Electrochemical Detection of Sulfhydryl Compounds. J Nanomat 2014(95):1-11. https://doi.org/10.1155/2014/695954

40. Blanco I (2018) Polyhedral Oligomeric Silsesquioxane (POSS)s in Medicine. J Nanomed 1(1):1002-1004

41. Silvestrini DR, Da Silveira TFS, Bicalho UO, Do Carmo DR (2015) Voltammetric Behavior of a Chemically Modified Silsesquioxane with 4-Amino-5-Phenyl-4h-[1,2,4]-Triazole3-Thiol and its Application for Detection of L-Dopamine. Int $\mathbf{J}$ Electrochem Sci 10:2839-2858

42. Pipi ARF, Do Carmo DR (2011) Voltammetric studies of titanium (IV) phosphate modified with copper hexacyanoferrate and electroanalytical determination of $\mathrm{N}$-acetylcysteine. J Appl Electrochem 41(2011):787-793. https://doi.org/10.1007/s10800-011-0296-x

43. Coşkun A (2006) The Synthesis of 4-Phenoxyphenylglyoxime and 4,4'-oxybis (phenylglyoxime) and Their Complexes with cu(II), ni(II) and co(II). Turk J Chem 30(4):461-469. https://doi.org/10. kim-06-30-4/kim-30-4-7-0601-16

44. Ibraheem H, Adel H, Ahmed A, Salih N, Salimon J, Graisa A, Farina Y, Yousif E (2010) Synthesis, characterization and antimicrobial activity of some metal ions with 2-thioacetic-5phenyl-1,3,4-oxadiazole. J Al-Nahrain Univ 13(1):43-47

45. Yousif E, Adil H, Farina Y (2010) Synthesis and characterization of some metal ions with 2-amino acetate benzothiazole. J Appl Sci Res 6(7):879-882
46. Williams RJJ, Hoppe CE, Zucchi IA, Romeo HE, Dell'erba IE, Gómez ML, Puig J, Leonardi AB (2014) Self-assembly of nanoparticles employing polymerization-induced phase separation. J Colloid Interface Sci 431:223-232. https://doi.org/10.1016/ j.jcis.2014.06.022

47. Hatakeyama T, Quinn FX (1999) Thermal analysis?: fundamentals and applications to polymer science? Wiley, Aulnay-sousBois

48. Zhang Z, Liang G, Lu T (2007) Synthesis and characterization of cage octa(aminopropylsilsesquioxane). J Appl Polymer Sci 103(4):2608-2614. https://doi.org/10.1002/app.25304

49. Do Carmo DR, Guinesi LS, Dias Filho NL, Stradiotto NR (2004) Thermolysis of octa(hydridodimethylsiloxyl)octasilsesquioxane in pyridine media and subsequent toluidine blue $\mathrm{O}$ adsorption. Appl Surf Sci 235(4):449-459. https://doi.org/10.1016/j.apsusc. 2004.02.061

50. Do Carmo DR, Paim LL, Dias Filho NL, Stradiotto NR (2007) Preparation, characterization and application of a nanostructured composite: Octakis (cyanopropyldimethylsiloxy)octasilsesquioxane. Appl Surf Sci 253(7):3683-3689. https://doi.org/10. 1016/j.apsusc.2006.07.080

51. Do Carmo DR, Dias Filho NL, Stradiotto NR (2004) Synthesis and preliminary characterization of octakis(chloropropyldimethy1siloxy)octasilsesquioxane. Mater Res 7(3):499-504. https://doi. org/10.1590/S1516-14392004000300020

52. Ayers JB, Waggoner WH (1971) Synthesis and properties of two series of heavy metal hexacyanoferrates. J Inorg Nucl Chem 33(3):721-733. https://doi.org/10.1016/0022-1902(71)80470-0

53. Baney RH, Itoh M, Sakakibara A, Suzuki T (1995) Silsesquioxanes. Chem Rev 95(5):1409-1430 